\title{
ANIMASI 3D RUTE JALUR BUS TRANS JOGJA TRAYEK 1A DAN 3 A BERBASIS ANDROID
}

\author{
Nurcahyani Dewi Retnowati, Hanik Atul Mutropin \\ Departemen Informatika \\ Sekolah Tinggi Teknologi Adisutjipto \\ Jl. Janti Blok R Adisucipto Yogyakarta \\ Email : nurcahyanidr@stta.ac.id
}

\begin{abstract}
The increase in the number of foreign tourists who are interested in visiting DIY significantly because this region has various world-class attractions, one of which is Malioboro. Currently, tourist infrastructure such as road access, transportation, and revitalization Malioboro has been built so as to facilitate the tourists and local tourists to travel to Malioboro. Transportation facilities that facilitate the tourists one of them is Trans Jogja bus. Trans Jogja bus route that supports transportation from the airport to Malioboro is Trans Jogja bus with route $1 A$ and route $3 A$ so that needed a medium that can give information of bus route of Trans Jogja from Airport to Malioboro and vice versa. The media in the form of three-dimensional animation based on mobile android that can be more informative, making it easier for tourists to understand the route of Trans Jogja bus route. Making interactive media using $3 d s$ max software with motion tween animation concept. the design and concept is then implemented in the form of animated movie. Application testing using black-box testing method. the results of the test show that the application is running well, the button on the application can be used, the route shown in accordance with the conventional map and can show the routes of bus routes according to the route used.
\end{abstract}

Keywords: interactive media, motion tween, black-box testing

\section{Pendahuluan}

Trans Jogja merupakan salah satu alternatif transportasi massa yang beroperasi di dalam Kota Yogyakarta sejak tahun 2008. Armada Trans Jogja yang dilengkapi dengan $\mathrm{AC}$ ini beroperasi setiap hari mulai pukul 05.30 - 21.30 WIB dan melayani 6 rute khusus yang beberapa diantaranya tidak dilalui bus kota. Seperti layaknya Trans Jakarta, Trans Jogja juga memiliki halte yang tersebar di berbagai tempat. Sedangkan pembedanya adalah Trans Jogja tidak memiliki koridor khusus seperti Trans Jakarta, melainkan masih bercampur dengan kendaraan lainnya. Kapasitas penumpang Trans Jogja adalah 20 penumpang duduk dan 20 penumpang berdiri. Sebagai alternatif transportasi dalam kota, Trans Jogja menjadi angkutan umum yang nyaman, mudah, murah, dan aman. Jika bingung dengan lokasi yang hendak dituju, kita bisa bertanya pada petugas Trans Jogja di halte ataupun petugas yang ada di dalam bis. Meski terkadang kedatangan armada tidak sesuai dengan jadwal yang tertera, setidaknya Trans Jogja masih menjadi angkutan umum yang bisa diandalkan baik dari segi kenyamanan maupun keamanan hingga saat ini [6]. Peta yang menjelaskan rute bus Trans Jogja hanya berupa peta konvensional. meskipun telah dapat diakses melalui website. 


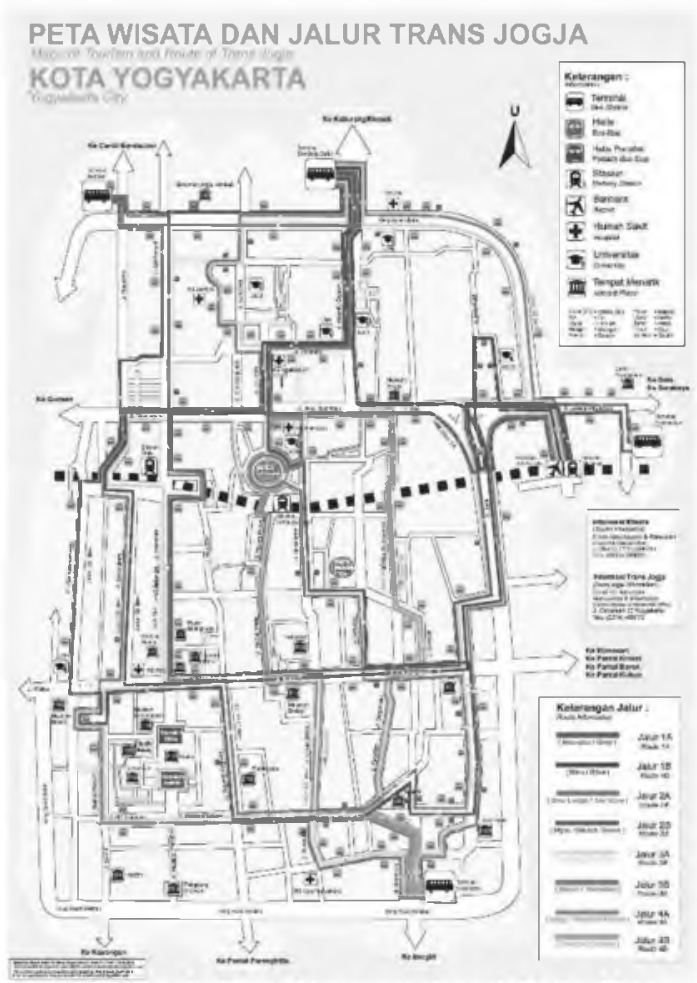

Gambar 1. Peta Konvensional Rute Bus

Trans Jogja [7]

Dalam penelitian ini dilakukan perancangan dan implementasi media interaktif peta rute bus Trans Jogja berbasis Android. Media interaktif berupa animasi dengan konsep motion tween menggunakan software 3ds max. Animasi motion tween merupakan pergerakan suatu objek dari keadaan awal sampai keadaan akhir, sebagai contoh pergerakan bola dari kiri ke kanan [1]. Digunakan software 3Ds max karena merupakan software visualisasi (modelling dan animasi) tiga dimensi yang populer dan serbaguna [2].

Trayek yang digunakan adalah trayek 1A dan 3A dikarenakan trayek tersebut dari bandara Adisutjipto menuju tempat wisata favorit (Malioboro) kemudian menuju kembali ke bandara Adisutjipto.

Saat ini, infrastruktur wisata seperti akses jalan, sarana transportasi, dan revitalisasi Malioboro telah dibangun sehingga memudahkan para wisman maupun wisatawan lokal untuk berwisata ke Malioboro.
2. Tinjauan Pustaka

Pada penelitian yang dilakukan oleh

Nurcahyani Dewi Retnowati dan Dwi Nugraheny (2014) berjudul Animasi 2 Dimensi Rute Perjalanan Bus Trans Jogja Berbasis Web, dijelaskan bahwa untuk mewujudkan transportasi yang baik maka diperlukan adanya infrastruktur dan faktor pendukung lainnya. Wilayah kodya Yogyakarta yang memiliki banyak alat transportasi umum, salah satunya bus Trans Jogja dimana setiap trayek memiliki rutenya masing-masing untuk mencapai ke berbagai tempat tujuan. Oleh karena itu diperlukan adanya media pendukung yang dapat memberikan informasi mengenai rute tiap trayek dan waktu kedatangan bus di setiap shelter Trans Jogja agar masyarakat dapat dengan mudah menentukan waktu berangkat dan sampai tempat tujuan. Informasi tersebut disampaikan dalam bentuk animasi dengan media yang menarik dan informatif. Penggunaan animasi berbasis web sebagai media informasi berupa rute perjalanan dan waktu kedatangan bus Trans Jogja di setiap shelter sehingga dapat digunakan sebagai salah satu pilihan lain untuk memperoleh informasi. Hasil uji pengguna dengan menggunakan kuisioner setelah dilakukan perhitungan mendapatkan hasil untuk poin $\mathrm{K}$ (Kurang) 28\%, poin C (Cukup) 64,67\%, poin B (Baik) 7,33\% dan poin SB (Sangat Baik) $0 \%$. Sehingga dari hasil tersebut dapat disimpulkan bahwa animasi 2 dimensi rute bus Trans Jogja berbasis web tampilannya sudah cukup menarik, mudah untuk digunakan dibandingkan peta konvensional, sehingga dengan adanya animasi 2 dimensi tersebut dapat membantu masyarakat ketika hendak menggunakan bus Trans Jogja [5].

\section{Metode Penelitian}

Dalam pembuatan animasi $3 \mathrm{D}$ rute bus Trans Jogja Trayek 1A dan Trayek 3A dilakukan analisis yang meliputi analisis kebutuhan perangkat lunak (software) dan perangkat keras (hardware), analisis kebutuhan sistem, dan analisis kebutuhan proses. Selain itu juga dilakukan perancangan yang meliputi perancangan flowchart, diagram konteks dan diagram alir data. Selanjutnya dilakukan perancangan sistem, yaitu merancang dan membuat 
animasi rute bus Trans Jogja trayek 1A dan 3A dari Bandara Adisucipto - Malioboro Bandara Adisucipto dengan menggunakan software 3Ds max untuk kemudian diimplementasikan menjadi suatu tayangan movie animasi berbasis mobile android. Tahap selanjutnya dilakukan pengujian pada aplikasi animasi tersebut dengan menggunakan metode black-box testing. Definisi menurut IEEE: Black Box Testing; Pengujian yang mengabaikan mekanisme internal sistem atau komponen dan fokus semata-mata pada output yang dihasilkan yang merespon input yang dipilih dan kondisi eksekusi. Pengujian Black Box dengan 3 langkah

a. Digunakan untuk menguji fungsi-fungsi khusus dari perangkat lunak yang dirancang.

b. Kebenaran perangkat lunak yang diuji hanya dilihat berdasarkan keluaran yang dihasilkan dari data atau kondisi masukan yang diberikan untuk fungsi yang ada tanpa melihat bagaimana proses untuk mendapatkan keluaran tersebut.

c. Dari keluaran yang dihasilkan, kemampuan program dalam memenuhi kebutuhan pemakai dapat diukur sekaligus dapat diiketahui kesalahankesalahannya.

4. Hasil dan Pembahasan

4.1 Analisis Kebutuhan Hardware dan Software

Perangkat keras yang digunakan dalam perancangan dan pembuatan animasi ini adalah sebagai berikut : Processor Intel(R) Core i3 3.7 Ghz, RAM 4096 MB, VGA HIS Ati RadeonR7 300 Series, Hard disk 500 GB, Layar 14". Perangkat lunak yang digunakan dalam perancangan sistem adalah sebagai berikut : Sistem Operasi Windows 8.0, 3D Studio Max 2012, Adobe Photoshop CS5, After Effect CS5 dan Unity.

\subsection{Flowchart dan Diagram Konteks \\ Flowchart sistem aplikasi perjalanan rute bus Trans Jogja trayek 1A dan trayek 3 A dapat dilihat pada Gambar 2.}

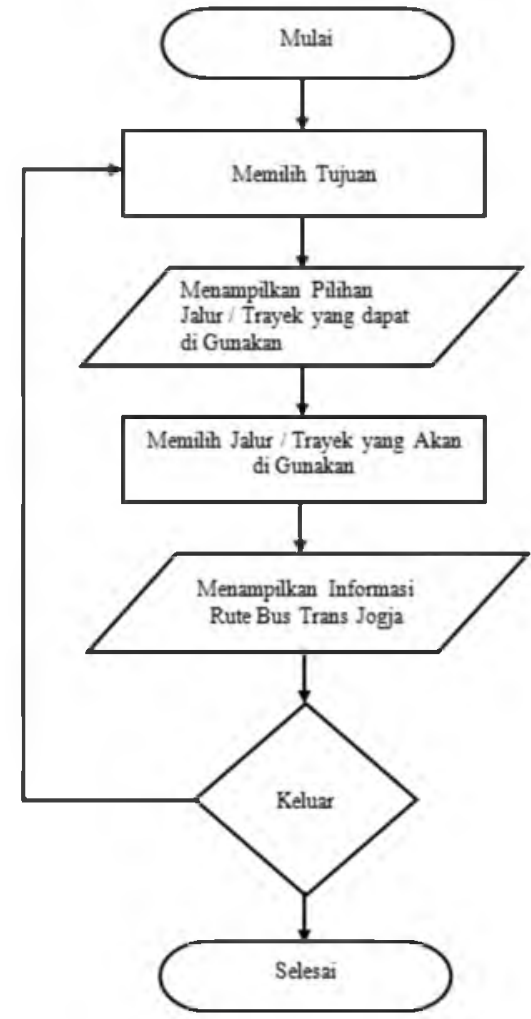

Gambar 2. Flowchart Sistem Aplikasi Perjalanan Rute Bus Trans Jogja Trayek 1A dan Trayek 3A

Diagram Konteks menggambarkan hubungan input / output antara sistem dengan dunia luarnya (kesatuan luar) [3]. Pada aplikasi Rute Bus Perjalanan Trans Jogja Berbasis Android ini, diagram konteks memiliki 1 (satu) kesatuan luar (entity), yaitu pengguna umum yang dapat mengakses aplikasi Rute Bus Perjalanan Trans Jogja Berbasis Android ini kapan saja, dan dimana saja.

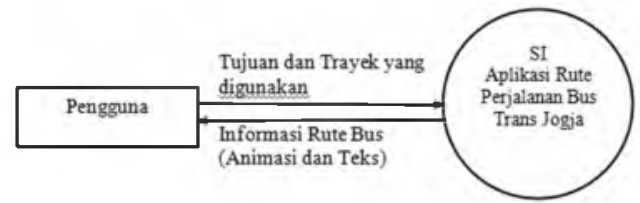

Gambar 3. Diagram Konteks Aplikasi Perjalanan Rute Bus Trans Jogja

Perancangan DAD digunakan untuk mengetahui alur data yang ada pada suatu sistem. Kelebihan DAD [4] diantaranya adalah mengkomunikasikan pengetahuan sistem yang ada dengan pengguna dan menganalisis sistem yang diajukan untuk 
menentukan apakah data-data dan proses yang diperlukan sudah ditetapkan, serta pemahaman tentang keterkaitan sistem dan subsistem satu sama lain. Diagram alir data level 0 seperti pada Gambar 4 merupakan pengembangan dari diagram konteks, dimana pada diagram ini dijelaskan bahwa setelah user memilih tujuan dan rute bus Trans Jogja maka akan diproses dan tampil informasi berupa tayangan video yang berisi animasi dan teks.

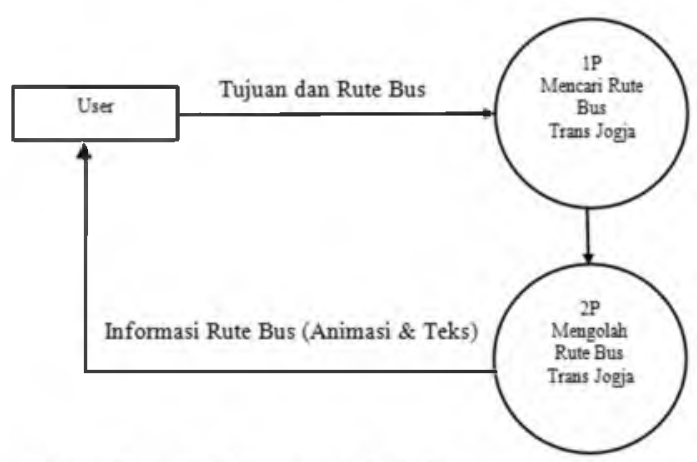

Gambar 4. Diagram Alir Data Level 0

\subsection{Rancangan Tampilan}

Rancangan tampilan antarmuka animasi rute perjalanan bus Trans Jogjaberbasis Android dapat dilihat pada Gambar 5 sampai dengan Gambar 6.

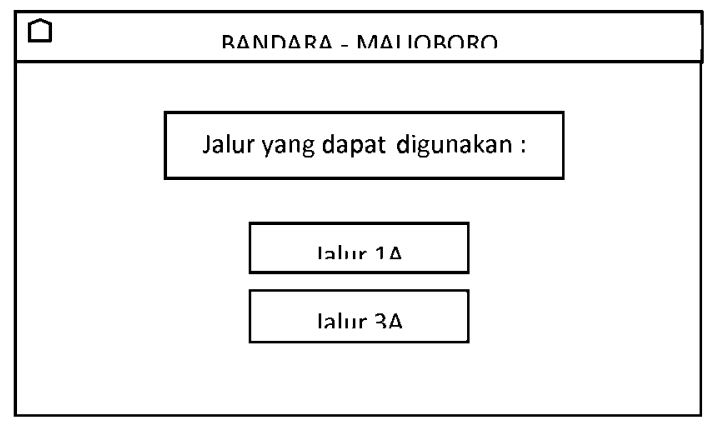

Gambar 5. Tampilan Rancangan Aplikasi Perjalanan Rute Bus Trans Jogja BandaraMalioboro

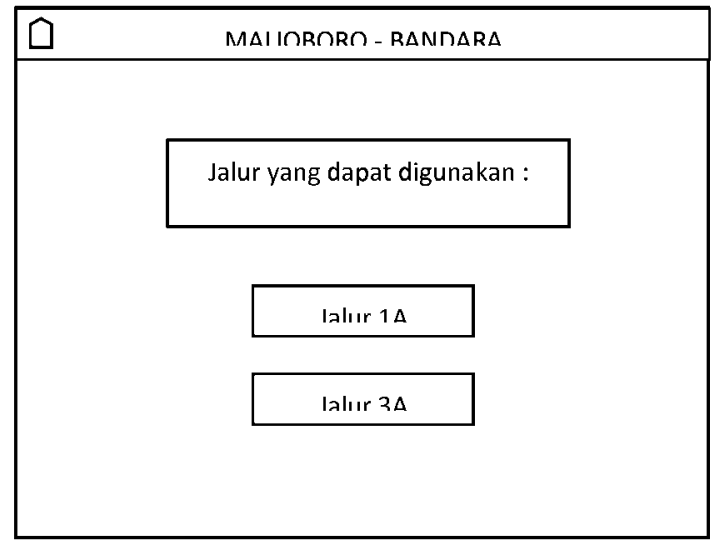

Gambar 6. Tampilan Rancangan Aplikasi Perjalanan Rute Bus Trans Jogja Malioboro - Bandara

4.4 Rute Bus Trans Jogja Trayek 1A dan Trayek $3 \mathrm{~A}$

Rute perjalanan yang dilewati oleh bus Trans Jogja trayek Bandara Adisutjipto - Malioboro - Bandara Adisutjipto adalah bus Trans Jogja trayek 1A dan trayek 3A adalah sebagai berikut:

Rute bus Trans Jogja trayek $1 \mathrm{~A}$ Bandara Adisutjipto - Malioboro - Bandara Adisutjipto: Bandara Adisutjipto - Halte Bandara Adisutjipto - Jl. Laksda Adisucipto - Halte JI. Solo (Jayakarta) - Jl. Janti - Halte Jl. Solo (Janti Flyover) - Jl. Laksda Adisucipto - Halte Jl. Solo (Jogja Bisnis) Halte Jl. Solo (Gedung Wanita) - Jl. Urip Sumoharjo - Halte Urip Sumoharjo - Jl. Jend. Sudirman - Halte Sudirman 1 - Halte Sudirman 2 - Tugu Jogja - Jl. P. Mangkubumi - Halte Mangkubumi 1 - Halte Mangkubumi 2 - Stasiun Tugu - Jl. Malioboro - Halte Malioboro 1 - Halte Malioboro 2 - Jl. Jend. Ahmad Yani - Halte Ahmad Yani - Jl. Senopati - Halte Senopati 2 - Jl. Sultan Agung - Halte Puro Pakualaman - Jl. Kusumanegara - Halte Kusumanegara 1 - Halte Kusumanegara 3 Gembiraloka - Halte Kusumanegara (Gedung Juang 45) - Jl. Janti - Halte Gedong Kuning (JEC) - JEC - Jl. Laksda Adisucipto - Halte Jl. Solo (Janti) - Halte Jl. Solo (Alfa) - Halte J1. Solo (Maguwo) - Bandara Adisutjipto - Halte Bandara Adisutjipto [6].

Rute 3A Bandara Adisutjipto Malioboro - Bandara Adisutjipto: Terminal Giwangan - Halte Giwangan - Jl. Kyai Gunomrico - Jl. Imogiri Timur - Jl. 
Tegalgendu - Halte Tegal Gendu 1 - Jl. Mondorakan - Jl. Nyi Pembayun - Jl. Kemasan - Jl. Gedong Kuning - Halte Gedong Kuning (Dep. Kehutanan) - Jl. Janti - Halte Gedong Kuning (JEC) - Jl. Laksda Adisucipto - Halte Jl. Solo (Janti) - Halte Jl. Solo (Alfa) - Halte Jl. Solo (Maguwo) Bandara Adisutjipto - Halte Bandara Adisutjipto - Jl. Raya Laksda Adisucipto Jl. Ring Road Utara - Halte Ring Road Utara (Disnaker) - Halte Ring Road Utara (Instiper 2) - Halte Ring Road Utara (UPN) - Jl. Anggajaya - Terminal Condongcatur - Halte Terminal Condongcatur - Jl. Anggajaya - Jl. Ring Road Utara - Halte Ring Road Utara (Manggung) - Jl. Kaliurang - Jl. Teknika Selatan - Jl. Kesehatan - Halte FK-UGM Jl. Bhineka Tunggal Ika - Jl. Persatuan Halte Jl. Kaliurang (Kopma UGM) - Jl. Terban - UGM - Jl. Cik Di Tiro - Halte Cik Di Tiro 1 - Jl. Suroto - Jl. Laksda Yos Sudarso - Halte Yos Sudarso - Jl. FM Noto Halte Kotabaru - Jl. Jend. Sudirman - Halte Sudirman 2 - Tugu - Jl. Diponegoro - Halte Diponegoro - Jl. Tentara Pelajar - Halte Tentara Pelajar 2 - J1. Tentara Rakyat Mataram - Jl. Jlagran Lor - Halte Jlagran Jl. Pasar Kembang - Jl. Malioboro - Halte Malioboro 1 - Halte Malioboro 2 - Jl. Jenderal Ahmad Yani - Halte Ahmad Yani Jl. KHA Dahlan - Halte KHA Dahlan 1 - Jl. Kyai Haji Wahid Hasyim - Taman Parkir Ngabean - Halte Ngabean - Jl. Kyai Haji Wahid Hasyim - Jl. Letnan Jenderal MT Haryono - Halte MT Haryono 1 - Jl. Mayjend. Sutoyo - Jl. Kolonel Sugiyono Halte Sugiono 1- Jl. Lowanu - Halte Lowanu - Jl. Sorogenen - Halte Sorogenen Jl. Tegal Turi - Halte Tegal Turi 1 - Jl. Imogiri Timur - Terminal Giwangan (istirahat 15 menit) - Halte Giwangan - Jl. Kyai Gunomrico - Jl. Imogiri Timur - Jl. Tegalgendu - Halte Tegal Gendu 1 - Jl. Mondorakan - Jl. Nyi Pembayun - Jl. Kemasan - Jl. Gedong Kuning - Halte Gedong Kuning (Dep. Kehutanan) - Jl. Janti - Halte Gedong Kuning (JEC) - Jl. Laksda Adisucipto - Halte Jl. Solo (Janti) - Halte Jl. Solo (Alfa)- Halte Jl. Solo (Maguwo) Bandara Adisutjipto [6].

4.5 Konsep Perancangan Animasi

Animasi yang akan ditampilkan pada aplikasi, menggunakan konsep animasi
Motion Tween dimana objek bus di frame pertama bergerak hingga frame terakhir. Objek bus tersebut berjalan dari halte ke halte, yaitu dari halte awal (keberangkatan) hingga halte terakhir (tempat tujuan).

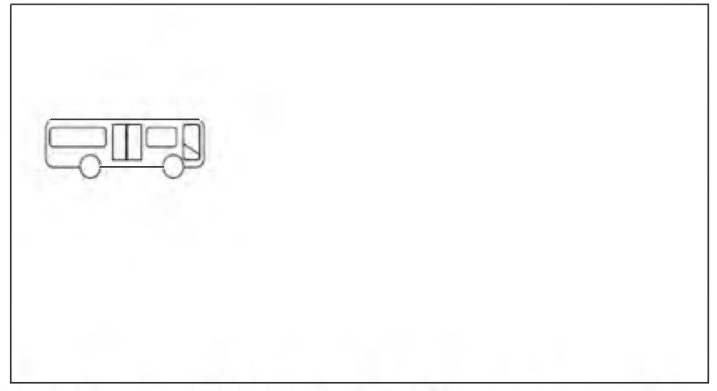

Gambar 7. Objek Bus Pada Frame Pertama

Pada Gambar 8 terlihat sebuah bus di frame awal (halte pemberangkatan) yang kemudian akan bergerak ke frame berikutnya sampai frame terakhir, yaitu halte yang dilewati bus Trans Jogja sampai akhirnya tiba di tempat tujuan.

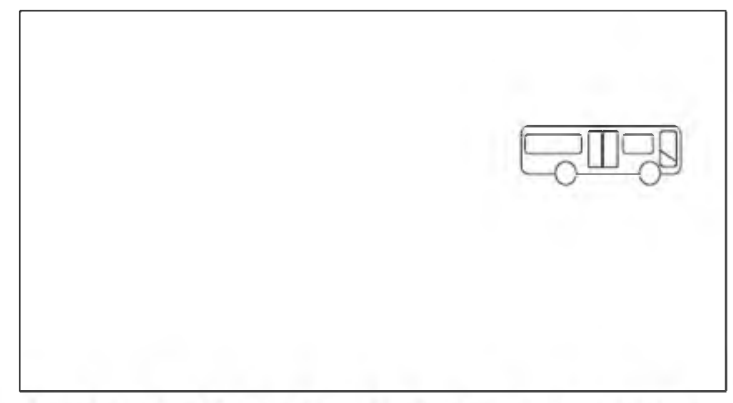

Gambar 8. Objek Bus Pada Frame Terakhir

Dengan memanfaatkan konsep animasi Motion Tween, maka objek bus digerakkan (Gambar 9) dari posisi awal atau halte pemberangkatan (Gambar 7) menuju halte terakhir atau halte-halte yang dilewati Bus Trans Jogja sampai akhirnya tiba ditempat tujuan (Gambar 8).

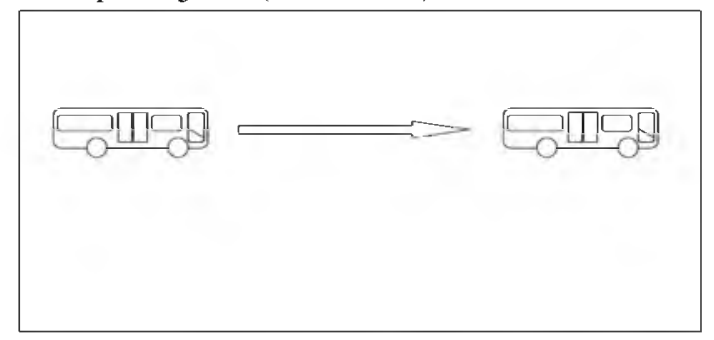

Gambar 9. Objek Bus Bergerak Dari Posisi Awal Ke Posisi Akhir 


\subsection{Implementasi}

Setelah aplikasi dibuka, secara otomatis akan muncul beberapa button yang dapat dipilih oleh pengguna aplikasi. Pilihan Button tersebut adalah Bandara-Malioboro, Malioboro-Bandara dan Help. Jika user berada pada halte asal Bandara dan akan menuju Malioboro, maka user dapat memilih button Bandara-Malioboro untuk mengetahui pilihan jalur bus yang dapat digunakan agar sampai ke Malioboro. Dan sebaliknya, jika user berada pada pada halte asal Malioboro dan akan menuju Bandara, maka user dapat memilih button MalioboroBandara untuk mengetahui pilihan jalur bus yang dapat digunakan agar sampai ke Bandara. Jika user merasa bingung mengenai bagaimana cara penggunaan aplikasi ini, user dapat memilih button help untuk mendapatkan informasi seputar aplikasi animasi rute perjalanan bus Trans Jogja ini. Tampilan menu rute dapat dilihat pada Gambar 10 dan Gambar 11.

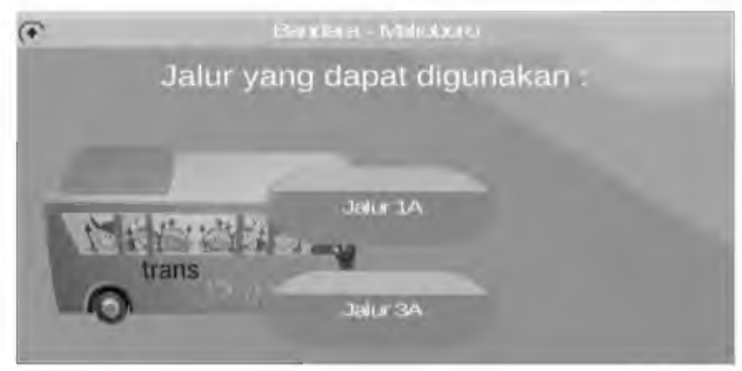

Gambar 10. Tampilan Menu Rute Bandara Adisutjipto - Malioboro yang Dilalui Bus

Trans Jogja Trayek 1A dan Trayek 3A

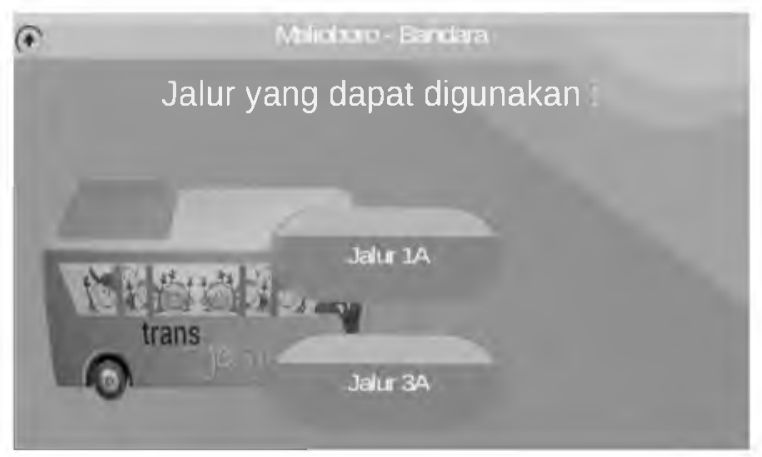

Gambar 11. Tampilan Menu Rute Malioboro - Bandara Adisutjipto yang Dilalui Bus Trans Jogja Trayek 1A dan Trayek 3A
Di setiap button pada tampilan menu rute baik rute Bandara Adisutjipto Malioboro maupun rute Malioboro Bandara Adisutjipto dapat diketahui rute perjalanan (trayek 1A dan trayek $3 \mathrm{~A}$ ), rute perjalanan tersebut meliputi halte atau shelter apa saja yang dilalui sehingga penumpangyang hendak turun di suatu halte atau shelter tertentu yang dilewati dapat melihat melalui aplikasi dan dapat pula melanjutkan perjalanan dengan trayek tersebut untuk menuju ke Malioboro atau ke Bandara Adisutjipto melalui aplikasi tersebut.

Video animasi rute bus dapat dilihat pada Gambar 12, Gambar 13 dan Gambar 14.

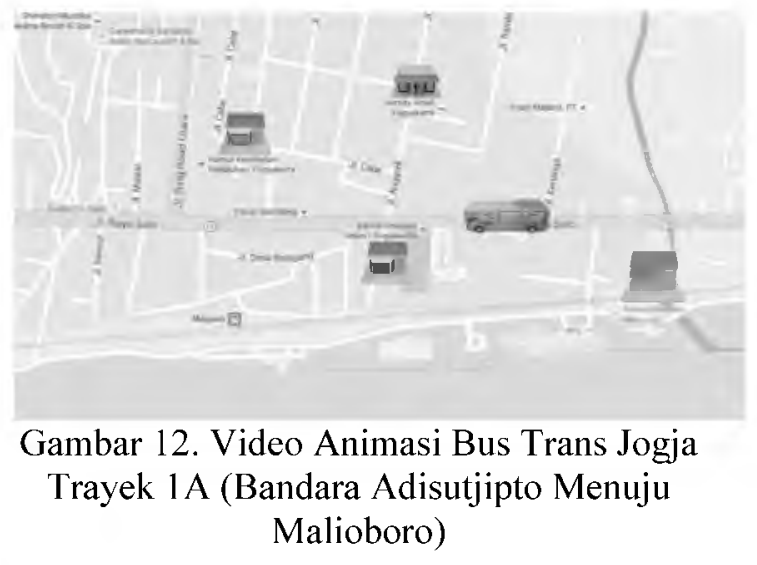

Sedangkan jika user memilih button Jalur 3A, maka agar sampai ke Malioboro user harus melewati beberapa halte, yaitu halte Ringroad Utara (Disnaker), Ringroad Utara (Instiper 2), Ringroad Utara (UPN), Terminal Condong Catur, Balai Manggung, RS Sardjito (FK UGM), Kopma UGM, Korem, SMP 5 (Kridosono), Bumi Putera, Diponegoro (Depan Kec. Jetis), Samsat, Jlagran (Stasiun Tugu), Malioboro 1 (Hotel Garuda), Malioboro 2 (Kepatihan), dan Malioboro 3 (Vredeburg). 


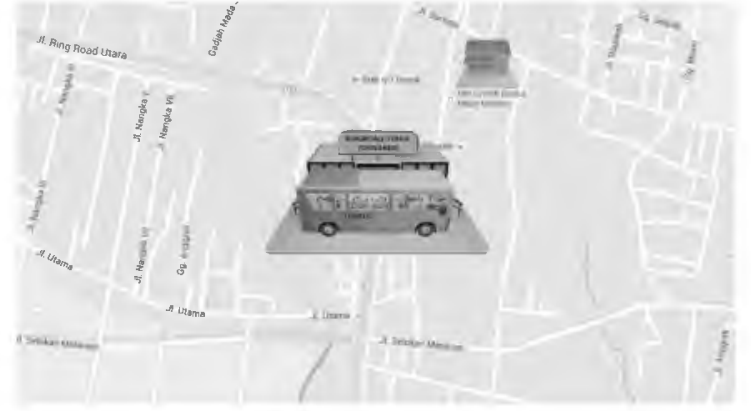

Gambar 13.Video Animasi Bus Trans Jogja Trayek 3A

Informasi yang disajikan dalam aplikasi ini tidak hanya berupa tulisan yang panjang dan membosankan mengenai haltehalte yang akan dilewati bus Trans Jogja. Namun informasi yang disajikan adalah berupa animasi bus berjalan dari halte menuju halte yang lain dengan menampilkan perjalanan nama halte sebelumnya.

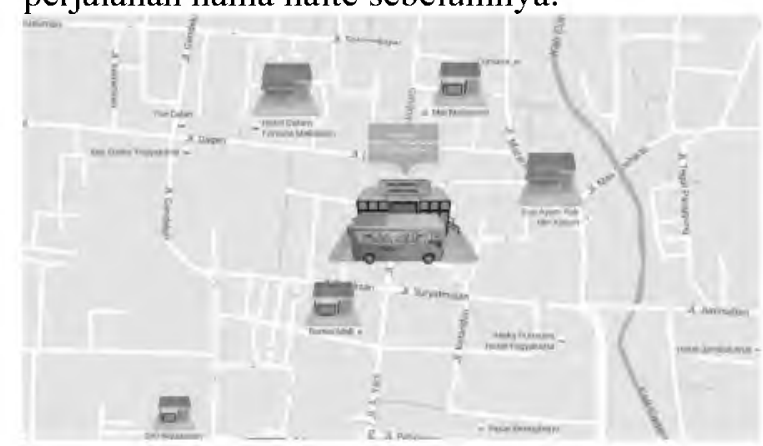

Gambar 14. Video Animasi Bus Trans Jogja Trayek 1A (Dari Malioboro Menuju Ke Bandara Adisutjipto)

Sedangkan jika user memilih button Jalur $3 \mathrm{~A}$, maka agar sampai ke Bandara Adisutjipto, user harus melewati beberapa halte yaitu Malioboro 2 (Kepatihan), Malioboro 3 (Vredeburg), Ahmad Dahlan (PKU), Terminal Ngabean, Jokteng Kulon (SMA 7), SD Pujokusuman (Sugiono 1), RS.Wirosaban, Terminal Giwangan, Tegal Gendu, Gedung Kuning (Dep. Kehutanan), JEC, Janti Utara, Alfa dan Maguwo.

\subsection{Pengujian}

Pengujian dari aplikasi rute perjalanan bus Trans Jogja trayek $1 \mathrm{~A}$ dan trayek 3A menggunakan black-box testing. Dari hasil pengujian dengan menggunakan black box testing, movie animasi rute bus Trans Jogja dapat menunjukkan rute perjalanan dari halte atau shelter awal (baik
Malioboro atau Bandara Adisutjipto), halte atau shelter apa saja yang dilalui dan halte atau shelter akhir (baik itu Bandara Adisutjipto dan Malioboro), button-button yang ada berfungsi dengan baik, aplikasi yang telah jadi sesuai alurnya dengan perancangan yang dilakukan sebelumnya baik itu flowchart sistem, diagram konteks, diagram alir data level 0 maupun dari segi perancangan tampilan.

\section{Kesimpulan}

Kesimpulan dari penelitian ini adalah sebagai berikut:

1. Aplikasi animasi rute perjalanan bus Trans Jogja berbasis android ini dapat menjadi pilihan untuk memperoleh informasi rute bus Trans Jogja selain menggunakan peta biasa. Informasi yang diberikan berupa halte atau shelter yang dilalui bus Trans Jogja trayek 1A dan trayek $3 \mathrm{~A}$.

2. Berdasarkan pengujian, dapat diketahui bahwa hasil keluaran (output) sesuai dengan yang diharapkan dan proses perancangannya mendukung output tersebut.

6. Saran

Saran untuk pengembangan penelitian selanjutnya diharapkan adanya penelitian animasi 3D untuk rute perjalanan bus Trans Jogja untuk trayek lainnya yang melalui destinasi selain Malioboro mengingat banyaknya wisatawan baik itu wisatawan domestik maupun wisatawan mancanegara yang berkunjung ke Yogyakarta.

\section{DAFTAR PUSTAKA}

[1] Gunawan, Bambi Bambang. 2013. NGANIMASI Bersama Mas Be!. Elex Media Komputindo. Jakarta.

[2] Hendratman Hendi., 2014. The Magic of $3 D$ Studio Max, Informatika. Bandung.

[3] Jogiyanto, H.M, 2005. Analisis dan Desain sistem Informasi : Pendekatan Teori dan Praktek Aplikasi Bisnis. CV. Andi Offset. Yogyakarta.

[4] Kendal \& Kendal, 2002. Analisis dan Perancangan Sistem, PT Intan Sejati.Klaten. 
[5] Retnowati, Nurcahyani Dewi, Dwi Nugraheny, 2014. Animasi 2 Dimensi Rute Perjalanan Bus Trans Jogja Berbasis Web. Jurnal Angkasa. Volume 6 Nomer 2 November 2014. Sekolah Tinggi Teknologi Adisutjipto. Yogyakarta.
[6] https:/www.yogyes.com/idlyogyakartatransportation/public/transjogja/, diakses pada tanggal 18 September 2017

[7] http://ishub.jogjaprov.go.id/transjogja, diakses pada tanggal 20 September 